\title{
ESOPHAGEAL APERISTALSIS AND ACHALASIA PRODUCED IN DOGS BY PROLONGED CHOLINESTERASE INHIBITION *
}

\author{
By LAURAN D. HARRIS, $\dagger$ W. D. ASHWORTH $\dagger \ddagger$ AND FRANZ J. INGELFINGER \\ (From the Evans Memorial and Massachusetts Memorial Hospitals and Department of Medicine, \\ Boston University School of Medicine, Boston, Mass.)
}

(Submitted for publication January 25, 1960 ; accepted March 1, 1960)

Considerable evidence suggests that cardiospasm, or achalasia of the esophagus, is a disease of the intrinsic innervation of that organ $(1-6)$. If so, a neurotoxic agent might produce a similar picture in experimental animals. This possibility is enhanced by the report of Koelle and Gilman (7) who, while studying the effects of prolonged administration to dogs of the anticholinesterase agent di-isopropylfluorophosphate (DFP), noted the appearance of objective evidences of dysphagia, esophageal stasis, and "cardiospasm." However, not all motor dysfunctions causing dysphagia and esophageal stasis in man are manifestations of cardiospasm, and no studies have been performed to show that DFP-induced canine "cardiospasm" is indeed analogous to the condition seen in man. Consequently, we undertook to see if 1) prolonged DFP administration does regularly produce an esophageal motor disorder in dogs, and 2), if so, to determine its nature and its similarity to human cardiospasm.

\section{METHODS}

Six adult mongrel dogs, 2 male and 4 female, weighing 15 to $18 \mathrm{~kg}$, were prepared with permanent cervical esophageal fistulas by the method of Ware and Howe (8). This preparation allows natural feeding with only minimal leakage, yet permits ready insertion of recording balloons, tubes and barium with no discomfort to the unanesthetized animal. Special care was taken during preparation of the fistula to identify and avoid injury to the vagi. All dogs ate and drank normally and maintained their weight before and after the fistulas were prepared. Weights were recorded weekly throughout the control and experimental periods. The dogs were easily trained to lie quietly for as long as 4 hours, unrestrained, while studies were done.

* Presented in part at the meeting of the American Federation for Clinical Research, Atlantic City, N. J., May 3, 1959.

† Work performed during tenure of traineeship from the National Institute of Arthritis and Metabolic Diseases, Bethesda, Md.

$\ddagger$ Present address: Inter-Mountain Clinic, Salt Lake City, Utah.
DFP ( 0.5 per cent in peanut oil) was administered intramuscularly in alternate hind legs three times weekly. Three dosage schedules were used: Dog 1 received 0.5 mg per kg; Dogs 2, 3 and 4, $0.3 \mathrm{mg}$ per $\mathrm{kg}$; and Dogs 5 and $6,0.2 \mathrm{mg}$ per $\mathrm{kg}$. The total dosage was calculated on the basis of the control weights and was not changed as the weight fluctuated during the experimental period. DFP was discontinued at the onset of severe skeletal muscle weakness or marked esophageal motor abnormalities. Serum and erythrocyte cholinesterase levels were periodically measured by Michel's method (9).

Balloon kymography was performed twice weekly during the control and experimental periods by means of an essentially isobaric system (10). At the first kymography session the balloon was allowed to advance into the stomach and then withdrawn until it was estimated to lie in the distal third of the esophagus. After the balloon's position was checked fluoroscopically, the tube was marked and during each subsequent study was introduced for the same distance. Since small parenteral doses of acetyl- $\beta$-methyl choline chloride (methacholine chloride) have been shown to cause a sustained contraction of the lower esophagus in human cardiospasm (11), this agent was administered intramuscularly at weekly intervals during the control and experimental periods to assess its effect on the balloon kymographic record. During the control period it was determined that $0.75 \mathrm{mg}$ of methacholine chloride consistently produced moderate but not excessively severe systemic effects, and this was chosen as the standard dosage.

Cine-fluororadiography, with aqueous barium sulfate suspension as contrast material, was performed during the control and experimental periods. The barium was introduced into the cervical esophagus by way of a soft rubber catheter in the fistula.

In Dogs 3 and 6, intraesophageal pressures in the lower esophagus were studied with open-tipped, water-filled, polyvinyl catheters of $1.4 \mathrm{~mm}$ ID. Simultaneous measurements were made from 3 tips spaced $3 \mathrm{~cm}$ apart. The tubes contained mercury markers to facilitate positioning at fluoroscopy. Pressure changes were transmitted to Sanborn pressure transducers and graphed on a Sanborn 4-channel recorder.

Microscopic anatomy of the esophagus of 3 normal dogs and of Dogs 1 and 5, which died after receiving DFP for 2 and 4 weeks, respectively, was studied in sections stained with hematoxylin and eosin. All but Dog 1 were autopsied within 30 minutes of death. Particular attention was directed to Auerbach's plexus. Postmortem change in 
size of the esophagus with resultant change in "concentration" of ganglion cells was minimized by measuring the esophagus in situ and maintaining it at this size during fixation. After fixation the esophagus was "rolled" so that sections representing the entire length of the esophagus could be encompassed on a single slide.

\section{RESULTS}

I. Control period. Balloon kymographic records showed a regular pattern of contractions at a rate of 6 to 8 per minute in 4 dogs. Two animals, however, (Dogs 1 and 3 ) had a consistently different pattern with the irregular occurrence of periods of inactivity varying in length up to 1 minute. Tho two types of control records are shown in Figure 1. It can be seen that about 20 $\mathrm{ml}$ of air enters the balloon before a contraction occurs; and in the essentially isobaric recording system used, this volume may be regarded as an expression of esophageal tonus (10). Both types of control records exhibited similar tonus, the figure obtained also being comparable with that recorded in the normal human esophagus. In all animals the balloon was rapidly propelled into the stomach when the tube was released.

Cine-fluororadiographic examination of the esophagus demonstrated active and effective peristalsis qualitatively similar to that seen in man.

Serum cholinesterase levels ranged from 0.97 to $1.52 \Delta \mathrm{pH}$ per hour, erythrocyte cholinesterase levels from 0.08 to $0.17 \Delta \mathrm{pH}$ per hour. For the individual animals the values were consistent.
II. Experimental period. After DFP was started, no effects were noted for 3 to 4 weeks, whereupon weakness and incoordination of the hind legs became apparent and progressed to a variable extent. The final degree of paresis varied markedly and bore little relationship to the total amount of DFP given (Table I). Dog 2 developed severe hind leg paresis while Dogs 3 and 4 , which received comparable doses, developed only-minimal symptoms. About one month after DFP was discontinued, hind leg strength in the surviving dogs gradually began to improve. This recovery was incomplete, however, and the more severely affected dogs had considerable weakness a year later.

Dogs 1, 4 and 5 manifested muscarinic effects of wheezing and dyspnea which were transiently present for about a week in Dog 4, but were noted to death in Dogs 1 and 5. These symptoms, as well as the weakness and incoordination, became much more severe after exercise. Muscular fibrillation was not seen. Transient urinary incontinence was observed in Dog 2, while Dog 1 had urinary and fecal incontinence for 4 to 5 days prior to death. Diarrhea was not observed. Small bowel balloon kymography was performed on Dog 6 eight weeks after DFP was stopped. The record obtained was entirely comparable with a record obtained from a normal dog as well as with normal human records. Although gastric peristalsis and emptying time were not specifically

CONTROL KYMOGRAPHIC RECORDS
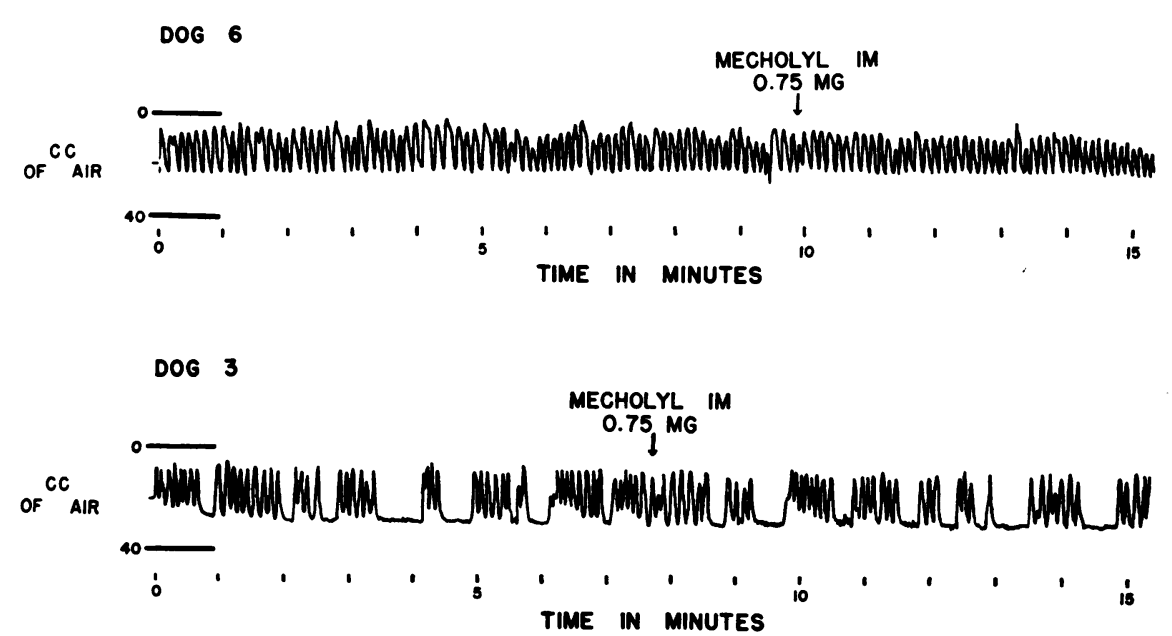

Fig. 1. Control BALLOON KYMOGRAPHIC RECORDS. 
TABLE I

Effect of di-isopropylfluorophosphate given three times weekly, in dogs

\begin{tabular}{|c|c|c|c|c|c|c|c|c|}
\hline Dog & Sex & Weight & $\begin{array}{c}\text { Single } \\
\text { dose }\end{array}$ & $\begin{array}{l}\text { No. of } \\
\text { doses } \\
\text { to onset } \\
\text { of musc. } \\
\text { weakness }\end{array}$ & $\begin{array}{c}\text { Total } \\
\text { dose } \\
\text { to onset } \\
\text { of musc. } \\
\text { weakness }\end{array}$ & $\begin{array}{c}\text { No. of } \\
\text { doses } \\
\text { to } \\
\text { esoph. } \\
\text { paralysis }\end{array}$ & $\begin{array}{l}\text { Total } \\
\text { dose } \\
\text { to esoph. } \\
\text { paralysis }\end{array}$ & Extent of paresis \\
\hline & & $\mathrm{kg}$ & $\mathrm{mg} / \mathrm{kg}$ & & $\mathrm{mg} / \mathrm{kg}$ & & $\mathrm{mg} / \mathrm{kg}$ & \\
\hline 1 & $\mathrm{~F}$ & 18 & 0.50 & 6 & 3.0 & 9 & 4.5 & Died \\
\hline 2 & $\mathbf{M}$ & 15 & 0.30 & 10 & 3.0 & 15 & 4.5 & Moderately severe \\
\hline 3 & $\mathrm{~F}$ & 15 & 0.30 & 13 & 3.3 & 17 & 5.1 & Minimal \\
\hline 4 & M & 19 & 0.30 & 13 & 3.3 & 17 & 5.1 & Minimal \\
\hline 5 & $\mathrm{~F}$ & 15 & 0.20 & 13 & 2.6 & 19 & 3.8 & Died \\
\hline 6 & $\mathrm{~F}$ & 16 & 0.20 & 10 & 2.0 & 19 & 3.8 & Moderately severe \\
\hline
\end{tabular}

recorded, no gross change was observed at fluoroscopy.

In all dogs, evidences of dysphagia with regurgitation of food and fluid and resultant weight loss began about one week after the first evidence- of hind leg weakness, i.e., four to five weeks after starting DFP. Terminally, Dogs 1 and 5 seemed able to swallow little if anything. In the surviving dogs, swallowing difficulties began to clear about four weeks after DFP was stopped, and their weight gradually returned to near control levels.

Changes in the balloon kymographic records were first noted shortly before the onset of evidences of dysphagia. These early changes consisted of prolonged periods of inactivity and a decreased tonus so that about $30 \mathrm{ml}$ of air was al- lowed to enter the balloon. Coincident with the signs of dysphagia, esophageal muscular activity virtually ceased, i.e., no contractions were observed for a 10 to 15 minute period, or at most no more than 10 irregularly occurring contractions during any 10 minute period. At this time the balloon remained stationary when released instead of being rapidly propelled into the stomach as in the control period. However, the balloon could be pushed into the stomach without difficulty.

With the cessation of esophageal muscular activity, DFP was stopped. Six to seven weeks later random, irregularly occurring waves began to appear. Figure 2 shows the sequence of tracings in a dog with a regular control record, and Figure 3 the sequence in a dog with an irregu-

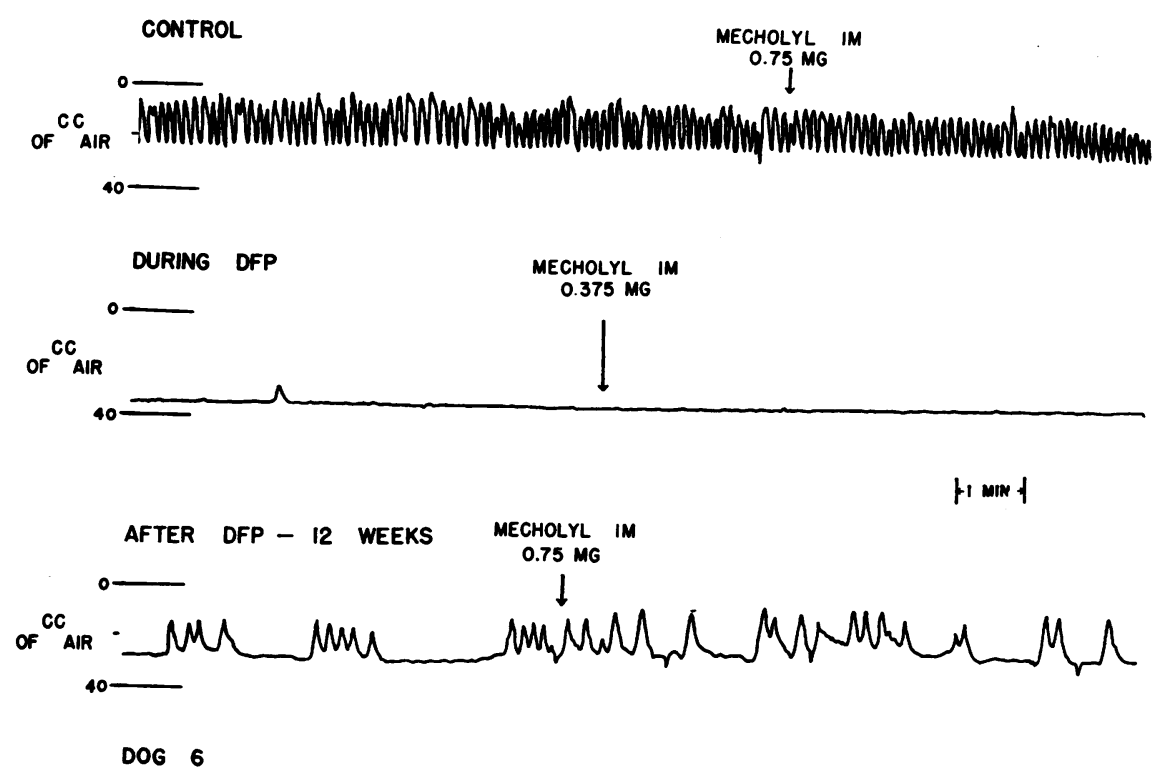

Fig. 2. Sequence of balloon KyMOGRAPHiC RECORDS IN A DOG With A REgular CONTROL RECORD. 

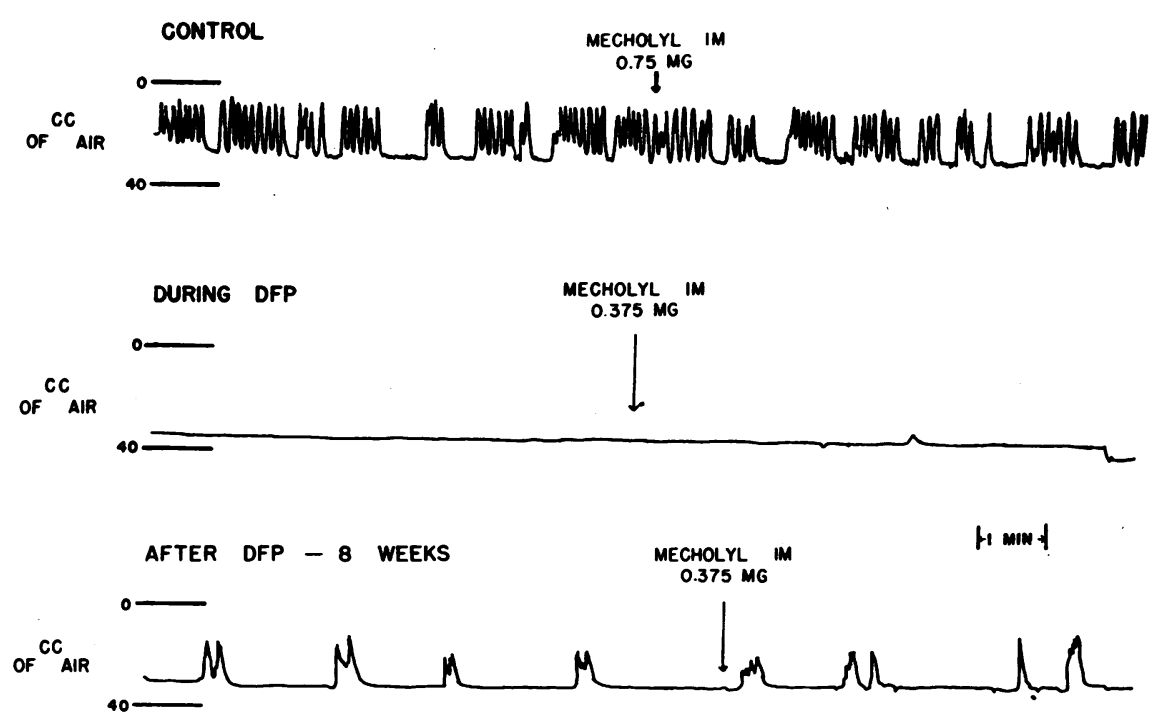

DOG 3

Fig. 3. Sequence of balloON KyMOGRAPHiC RECORdS IN A DOG With AN IRREgular CONTROL RECORD.

lar control record. Both show greatly decreased of a year esophageal motor activity increased, but tonus during the aperistaltic period with slight increase in tonus when some activity had returned. This sequence occurred in all dogs. In the course

did not return to normal.

Intramuscular methacholine chloride produced no esophageal effects during either the control or

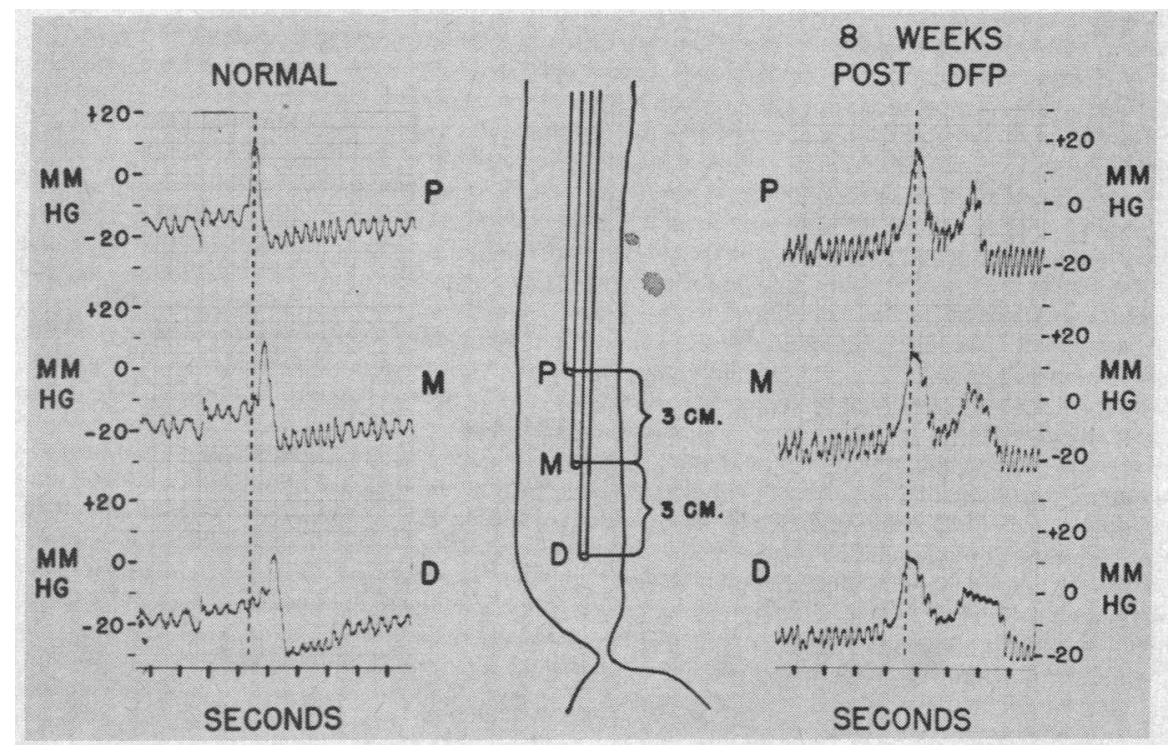

FIG. 4. NORMAL AND POST-DI-ISOPROPYLFLUOROPHOSPHATE (DFP) INTRALUMINAL PRESSURE RECORDS FROM THE DISTAL ESOPHAGUS. Deglutition occurred approximately two seconds before the positive pressure deflection started. Note the progressive peak of pressure (peristalsis) in the normal record as contrasted to simultaneous peaks of pressure recorded 8 weeks after DFP was stopped. 
experimental period. While DFP was being given, it became necessary to reduce the dosage of methacholine chloride from the standard $0.75 \mathrm{mg}$ to as low as $0.25 \mathrm{mg}$ to prevent excessively severe systemic reactions. After DFP was stopped, it was possible to increase the dose slowly to control levels. Dog 6 was given $2.0 \mathrm{mg}$ of methacholine chloride on one occasion while she was receiving DFP and on another after DFP was stopped. Each time profuse salivation, hyperpnea, agitation and restlessness, vomiting and defecation appeared, but no esophageal effects were recorded.

Cine-radiographic examination of the esophagus at the peak of DFP effect showed striking changes. Barium suspension introduced through the fistula with the dog horizontal remained pooled in the body of the esophagus and no muscular activity was seen. The addition of more barium suspension did not result in any motor response; the organ merely dilated. To assess the effects of gravity, the animals were then held upright and examined at intervals without the addition of more barium. Invariably, most of the column of barium suspension remained in the esophagus after the animals had been upright for 15 minutes. The esophagus was usually found to be empty after the animals had been held upright for 20 to 30 minutes.

Six to seven weeks after DFP was stopped, when kymographic records showed some return of motor function, the radiologic picture of esophageal dilatation persisted. At this time, however, rapid distention of the esophagus with barium suspension resulted in recurrent segmental contractions, brief in duration, that moved the barium both orally and, to some extent, into the stomach. On occasions these contractions appeared to be distally progressive, but they did not completely occlude the lumen or empty the esophagus. With the passage of these distally progressive but ineffectual waves the barium suspension did not appear to be pushed ahead of the contraction but was merely displaced proximally. This resulted in the interesting picture of a distally progressive contractile wave but proximal or retrograde flow of barium suspension. This retrograde flow occurred even when the animals were in the upright position. In the interval between contractions there were prolonged periods of inactivity, and the esophagus remained filled with barium.

Control intraluminal pressure records showed a distally progressive peak of pressure as a peri-
NORMAL

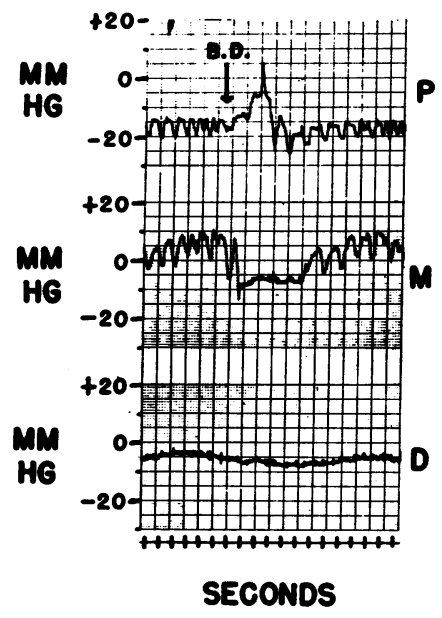

2 WEEKS POST DFP

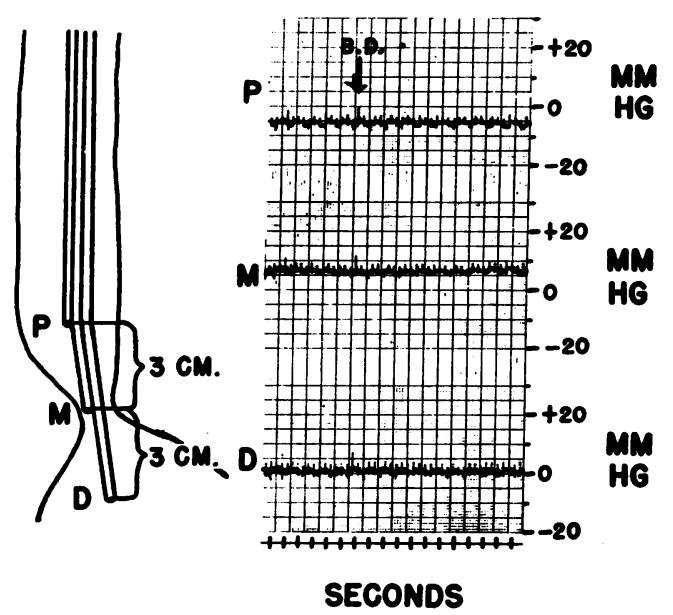

B.D. = BALLOON DISTENTION

Fig. 5. INTRAESOPHAGEAL PRESSURE RECORDS WITH THE MIDDLE TIP IN THE GASTROESOPHAGEAL SPHINCTERIC AREA. In the normal record, distention of a $40 \mathrm{ml}$ capacity balloon in the upper esophagus or deglutition regularly resulted in a sharp drop of pressure within a second. Although the zone of elevated pressure was found in the recording made two weeks after DFP was stopped, no drop of pressure occurred following balloon distention or deglutition. 
staltic wave traveled the esophagus, whether initiated by a dry swallow, a wet swallow, or by distention of a balloon placed in the upper esophagus. This is in contrast to the post-DFP (i.e., recovery) period when peaks of pressure were recorded in all three tips simultaneously (Figure 4). Intraluminal pressures recorded during the height of DFP effect showed only the expected respiratory and cardiac effects without evidence of esophageal muscular activity.

Since the pressure characteristics of the gastroesophageal junctional area had not been investigated in the original group of six, a seventh dog was also given DFP after control pressure studies of the junctional area. In the control period, a zone of elevated pressure which exhibited a sharp drop in pressure in response to deglutition was recorded, findings similar to those previously reported by Schlegel and Code (12). In addition, this drop in pressure could be elicited by rapid distention of a balloon of about $40 \mathrm{ml}$ capacity placed in the upper esophagus (normal, Figure 5). This similarity of response to both deglutition (primary peristalsis) and balloon distention (secondary peristalsis) has previously been reported in the normal human (13). At the height of DFP effect, a similar zone of elevated resting pressure was demonstrated at the gastroesophageal junctional area. However, neither deglutition nor rapid distention of a balloon placed in the upper esophagus resulted in a drop of pressure (postDFP, Figure 5).

Postmortem examination of the two animals that died during the course of the study showed the esophagus to be dilated but to have no mucosal changes. The remainder of the gastrointestinal tract appeared normal. The number of myenteric ganglion cells of Auerbach's plexus in each of several slides, representing the entire length of esophagus in three normal dogs and the two DFP dogs, was counted. The normal dogs averaged 20, the DFP dogs 15 ganglion cells per slide, an inconclusive difference.

\section{DISCUSSION}

A sharp distinction must be drawn between the acute pharmacologic effects of DFP and the residual effects following prolonged administration of the agent. Acutely, DFP phosphorylates and thereby inactivates cholinesterase. The unopposed neurotransmitter acetylcholine thereupon produces continued depolarization of the motor endplate with resultant neuromuscular block, a sequence which has been established particularly for skeletal muscle (14). This acute effect of DFP is usually considered to be completely reversible $(14,15)$. However, a prolonged and perhaps irreversible motor disorder of the esophagus and hind legs was evident in our dogs long after DFP administration was stopped and persisted in the face of normal serum and erythrocyte cholinesterase levels, i.e., at a time when tissue cholinesterase levels had presumably returned to normal. This effect of prolonged cholinesterase inhibition has been noted in experimental animals $(7,16)$ and also following long continued exposure to anticholinesterases in man (17-19). It would thus appear that either prolonged excess of the neurotransmitter substance induced by the anticholinesterase agent or the anticholinesterase agent itself may permanently damage some link in the chain of neuromuscular events. Whether the site of this damage is the same as the site of the acute effect is unknown.

The esophageal disorder produced in dogs following prolonged DFP administration resembles cardiospasm in man in several respects. At the height of DFP effect, the esophagus is dilated, peristalsis is absent, the lower esophageal sphincter does not relax in response to either a swallow or balloon distention of the upper esophagus, and residues of barium suspension remain in the esophagus in the face of gravity. Thus the dogs exhibit two cardinal features of human cardiospasm: aperistalsis and failure of relaxation ("achalasia") of the gastroesophageal sphincter. A crucial difference exists, however, between spontaneous human cardiospasm and the motor abnormalities following prolonged DFP administration. In human cardiospasm, exhibition of a small dose of methacholine is followed by a strong, nonpropulsive contraction of the esophagus, but no esophageal effects are noted in the dogs exposed to DFP.

One explanation for the lack of response to methacholine noted in our dogs might be that cardiospasm and prolonged DFP administration 
affect neuromuscular transmission at different sites. If present concepts of the nature of cardiospasm are correct, the basic lesion is a poverty of normal ganglion cells of Auerbach's plexus amounting to a "denervation" of the esophagus $(1,3,6)$. The muscle cells presumably remain normally polarized and therefore sensitive to depolarizing agents. Since the neuromuscular block produced by acute DFP intoxication is ascribed to an excess of acetylcholine, it is not surprising that the addition of another depolarizing agent in the form of methacholine during the period of DFP administration fails to elicit a contraction. Unfortunately, such a tidy neurochemical difference cannot be drawn between cardiospasm and the condition seen following prolonged DFP administration, but if the block in this condition is also due to failure of repolarization of the motor end-plate, then methacholine would not be expected to result in contraction.

Another factor that might alter the results of prolonged DFP administration is the different structure of the esophagus in man and dog; although similarly innervated, the human esophagus contains predominantly smooth, the canine esophagus predominantly skeletal, muscle (20). How important this histologic difference might be, however, is difficult to assess. Regardless of its muscular morphology, the canine esophagus possesses an innervation typical of intestinal smooth muscle with a myenteric plexus extending over its entire length. Moreover, as judged by balloon kymograms and measurements of peristaltic and lower esophageal sphincter activity, the canine esophagus appears to function in a very similar fashion to the human esophagus. From a functional point of view, therefore, the striated canine esophagus appears to be more comparable with smooth muscle (as in the human esophagus) than with skeletal muscle (as in the gastrocnemius). One is tempted to use the difference in musculature to explain why we observed marked esophageal effects following prolonged DFP intoxication without obvious changes in the remainder of the gastrointestinal tract. However, anticholinesterase agents, including DFP, have been shown to affect the smooth muscled gastrointestinal tract of experimental animals $(7,21)$ and also man $(14,15$, 22).
Other attempts to produce experimental cardiospasm in animals have depended upon either a direct surgical attack on the esophagus or its nerve supply $(23,24)$ or the injection of a sclerosing agent into the esophageal wall (25). The significance of such procedures is difficult to assess, however, since gross cicatricial or inflammatory effects are also necessarily produced. In addition, the dynamics of the resultant esophageal disorders have not been analyzed in detail nor has the response to methacholine been determined. The major implication of our study is that a severe esophageal motor dysfunction with two features typical of human cardiospasm can be produced experimentally by an agent known to affect neuromuscular transmission. Moreover, this motor abnormality can be produced without concomitant gross or even microscopic change in esophageal structure. It is therefore possible that a condition resembling cardiospasm in all respects, or even the condition in man itself, may be produced by a neurotoxin that affects the proper site in the sequence of neuromuscular tansmission.

SUM MARY

The prolonged administration of the anticholinesterase agent di-isopropylfluorophosphate to dogs resulted in 1) esophageal aperistalsis, and 2) failure of relaxation of the lower esophageal sphincter in response to swallowing and esophageal balloon distention. These effects persisted for months after the administration of di-isopropylfluorophosphate was stopped. While the esophageal disorder produced resembled human cardiospasm, the characteristic response of the human cardiospastic esophagus to methacholine chloride was lacking. It is postulated that difference in site of neurochemical lesion could account for this discrepancy and that neurotoxins acting at somewhat different sites could reproduce the picture of spontaneous human cardiospasm in its entirety.

\section{ACKNOWLEDGMENT}

We wish to acknowledge our indebtedness to Dr. A McGhee Harvey who called our attention to the report of Koelle and Gilman (7), and to Dr. Chester W. Howe for preparing the esophageal fistulas. DFP was generously supplied by Merck, Sharp and Dohme Research Laboratories, West Point, $\mathrm{Pa}$. 


\section{REFERENCES}

1. Lendrum, F. C. Anatomic features of cardiac orifice of the stomach, with special reference to cardiospasm. Arch. intern. Med. 1937, 59, 474.

2. Rake, G. W. On the pathology of achalasia of the cardia. Guy's Hosp. Rep. 1927, 77, 141.

3. Cross, F. S. Pathologic changes in megaesophagus (esophageal dystonia). Surgery 1952, 31, 647.

4. Etzel, E. Megaoesophagus and its neuropathology; clinical and anatomo-pathological research. Guy's Hosp. Rep. 1937, 87, 158.

5. Cameron, J. A. Oesophagectasia in a child. Arch. Dis. Childh. 1927, 2, 358.

6. Kramer, P., and Ingelfinger, F. J. Cardiospasm, a generalized disorder of esophageal motility. Amer. J. Med. 1949, 7, 174.

7. Koelle, G. B., and Gilman, A. Chronic toxicity of di-isopropylflurophosphate (DFP) in dogs, monkeys and rats. J. Pharmacol. exp. Ther. 1946, 87, 435.

8. Ware, P. F., and Howe, C. W. Experimental esophageal and pharyngocervical fistula. Arch. Surg. (Chicago) 1951, 63, 229.

9. Michel, H. O. An electrometric method for the determination of red blood cell and plasma cholinesterase activity. J. Lab. clin. Med. 1949, 34, 1564.

10. Kramer, P., and Ingelfinger, F. J. Motility of the human esophagus in control subjects and in patients with esophageal disorders. Amer. J. Med. 1949, 7, 168.

11. Kramer, P., and Ingelfinger, F. J. Esophageal sensitivity to mecholyl in cardiospasm. Gastroenterology 1951, 19, 242.

12. Schlegel, J. F., and Code, C. F. Pressure charactertistics of the esophagus and its sphincters in dogs. Amer. J. Physiol. 1958, 193, 9.

13. Fleshler, B., Hendrix, T. R., Kramer, P., and Ingelfinger, F. J. The characteristics and similarity of primary and secondary peristalsis in the esophagus. J. clin. Invest. 1959, 38, 110.
14. Grob, D. The manifestations and treatment of poisoning due to nerve gas and other organic phosphate anticholinesterase compounds. A.M.A. Arch. intern. Med. 1956, 98, 221.

15. Grob, D., and Harvey, J. C. Effects in man of the anticholinesterase compound Sarin (isopropyl methyl phosphonofluoridate). J. clin. Invest. 1958, 37,350 .

16. Hunt, C. C., and Riker, W. F., Jr. The effect of chronic poisoning with di-isopropyl fluorophosphate on neuromuscular function in the cat. J. Pharmacol. exp. Ther. 1947, 91, 298.

17. Petty, C. S. Organic phosphate insecticide poisoning. Residual effects in two cases. Amer. J. Med. 1958, 24, 467.

18. Bidstrup, P. L., Bonnell, J. A., and Beckett, A. G. Paralysis following poisoning by a new organic phosphorus insecticide (Mipafox): Report on 2 cases. Brit. med. J. 1953, 1, 1068.

19. Glasson, J., and Stelling, F. H. An unusual cause for paralysis of the extremities. Sth. med. J. (Bgham, Ala.) 1956, 49, 1325.

20. Ingelfinger, F. J. Esophageal motility. Physiol. Rev. 1958, 38, 533.

21. Lindenberg, R. Morphologic alterations in the spinal cord of cats after subacute exposure to DFP (diisopropylphosphofluridate). Chemical Corps Medical Laboratory Research Report, no. 235.

22. Walsh, A. DFP in the treatment of paralytic ileus. Irish J. med. Sci. 1957, no. 377, 241.

23. Agrifoglio, M. Ricerche sperimentali sulla dilatazione diffusa dell' esofago. Arch. ital. Chir. 1931, 28, 337.

24. Hwang, K., Essex, H. E., and Mann, F. C. A study of certain problems resulting from vagotomy in dogs with special reference to emesis. Amer. J. Physiol. 1947, 149, 429.

25. Deloyers, L., Cordier, R., and Duprez, A. A new approach to the physiology of so-called cardiospasm: Experimental production of cardiospasm in cats after destruction of Auerbach's plexus. Ann. Surg. 1957, 146, 167. 